

\section{DISCLAIMER}

This report was prepared as an account of work sponsored by an agency of the United States Government. Neither the United States Government nor any agency Thereof, nor any of their employees, makes any warranty, express or implied, or assumes any legal liability or responsibility for the accuracy, completeness, or usefulness of any information, apparatus, product, or process disclosed, or represents that its use would not infringe privately owned rights. Reference herein to any specific commercial product, process, or service by trade name, trademark, manufacturer, or otherwise does not necessarily constitute or imply its endorsement, recommendation, or favoring by the United States Government or any agency thereof. The views and opinions of authors expressed herein do not necessarily state or reflect those of the United States Government or any agency thereof. 


\section{DISCLAIMER}

Portions of this document may be illegible in electronic image products. Images are produced from the best available original document. 


\section{LEGAL NOTICE}

This report was prepared as an account of work sponsored by the United States Government. Neither the IInited States nor the Energy Research and Development Administration, nor any of their employees, nor any of their contractors, subcontractors, or their employees, makes any warranty, expressed or implied, or assumes any legal liability or responsibility for the accuracy, completeness or usefulness of any information, apparatus, product or process disclosed, or represents that its use would not infringe privately owned rights.

Printed in the United States of America Available from the

National Technical Information Service U. S. Department of Commerce Springfield, Virginia 22161

Price: Printed Copy $\$ 4.50$ Microfiche $\$ 3.00$

Price Is Subject to Change Without Notice 
Printed

April 16, 1977
RFP-2570

UC-41 HEALTH AND SAFETY

TID-4500-R65

\section{WOUND-COUNTING SYSTEMS FOR THE MEASUREMENT AND ISOLATION OF PLUTONIUM AND AMERICIUM}

William H. Tyree

Thomas H. Bell

Robert L. Lane

John B. Macaluso

Health Sciences and Industrial Safety, RADIATION INSTRUMENTATION GROUP

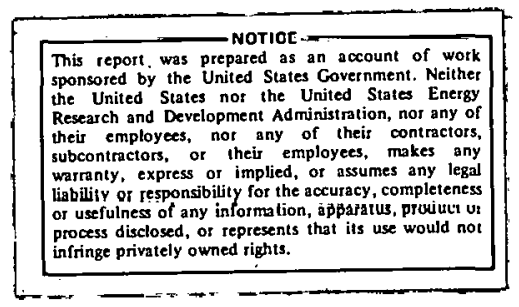

ROCKWELL INTERNATIONAL

ATOMICS INTERNATIONAL DIVISION ROCKY FLATS PLANT

P.O. BOX 464

GOLDEN, COLORADO 80401

Prepared under Contract EY-76-C-04-3533

for the

Albuquerque Operations Office

U, S, Energy Research and Development Administration 


\section{THIS PAGE}

\section{WAS INTENTIONALLY \\ LEFT BLANK}




\section{CONTENTS}

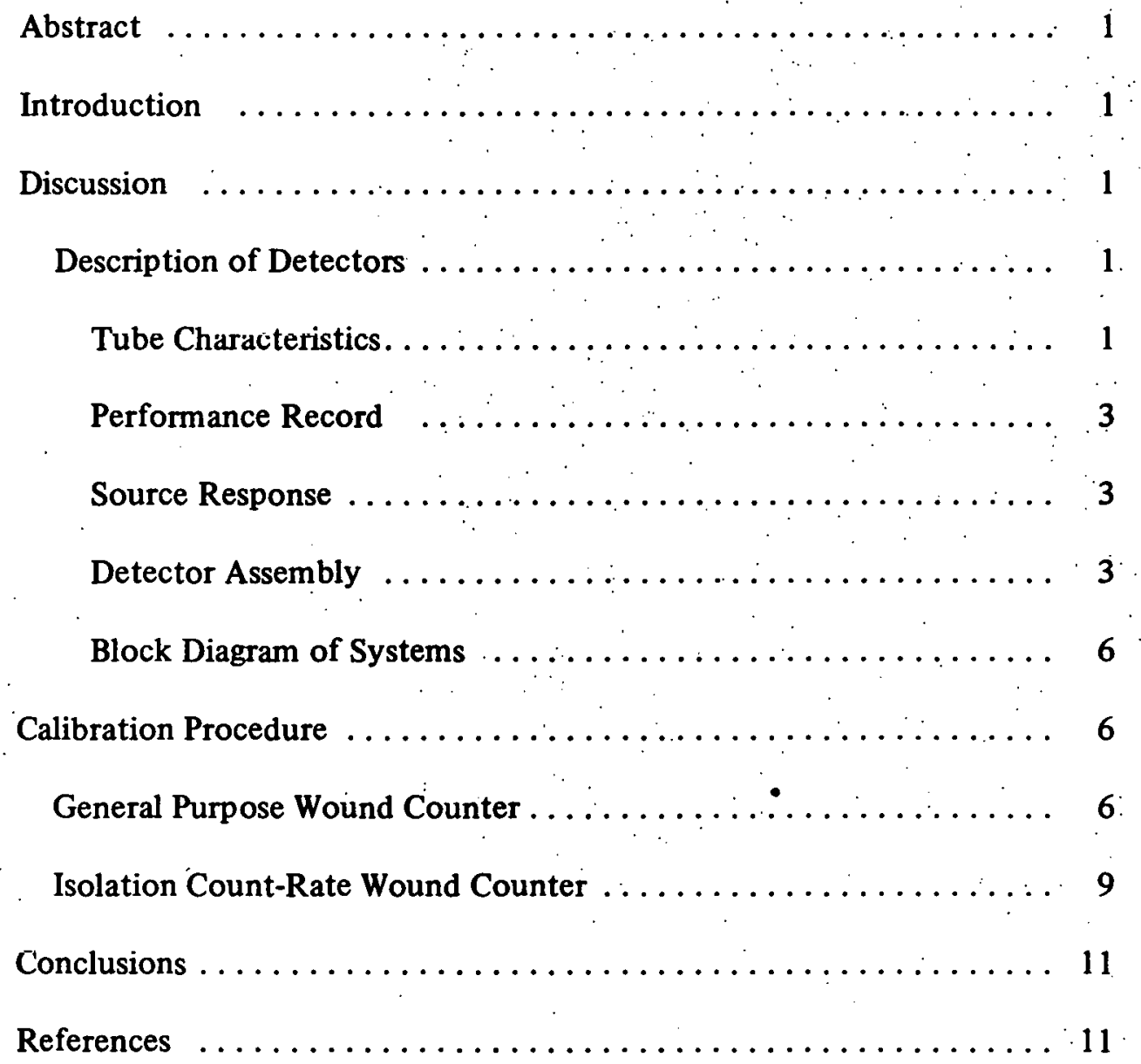




\section{THIS PAGE}

\section{WAS INTENTIONALLY LEFT BLANK}




\title{
WOUND-COUNTING SYSTEMS FOR THE MEASUREMENT AND ISOLATION OF PLUTONIUM AND AMERICIUM
}

\author{
William H. Tyree, Thomas H. Bell, Robert L. Lane, and John B. Macaluso
}

\begin{abstract}
Described are newly developed woundcounting systems which provide: (1) a high sensitivity for the detection and quantification of $\mathrm{X}$-ray emissions from wounds contaminated with plutonium or americium; and (2) for the location of deposition of radioactive material within a wound, as required by surgery. The systems are used in the medical facility at the Rocky Flats Plant. Work efforts over the past 20 years have concentrated on improving detection limits by reducing and stabilizing the background counting rate. The developments over the last three years have resulted in a family of instruments with excellent operational characteristics, complementary package design, easy maintenance, and reliable operation.
\end{abstract}

\section{INTRODUCTION}

The new systems evolved from a counting device using rebuilt airborne radiation counting instruments, with vacuum-tube amplifiers and scalers. Incorporated in the new systems are integrated circuits, plug-in nuclear instrument modules (NIM). with gallium arsinide light-emitting diode (LED) digital readouts. Using 13-stage photomultiplier tubes, a lower background count and better resolution can be obtained. Built by EMRSchlumberger, ${ }^{1}$ the tubes consist of bi-alkali photocathodes (No. 510N-01-13) with brazed ceramic dynodes, and include internal dy node resistors and decoupling capacitors. As compared to the 10-stage tubes ${ }^{2}$ used initially, the 13-stage tubes provide much lower ambient temperature dark current.

\footnotetext{
${ }^{1}$ EMR-Schlumberger. "Preliminary Specifications, Model 510N-01-13." Photo Electric, Division of Weston Instruments, Box 44, Princeton, New Jersey. 08540. April 1973.

${ }^{2}$ Phntomultiplier Tube, RCA Technical Publication PIT-700B. Radio Corporation of America, New York. December 1971.
}

\section{DISCUSSION}

\section{Description of Detectors:}

The 13-stage photomultiplier tube (PMT) used in the new wound counters provides an improved background performance over other tubes. The data comparing the three types of tubes are shown in Figure 1.

Figures 2 and 3 show the relative response of two types of tubes: the bi-alkali 10-stage and the bi-alkali 13-stage photomultiplier tubes, for detecting the 17-kiloelectron volt (keV) (average) energy and $59.54 \mathrm{keV}$ photon energies of plutonium and americium. Shown also are the typical analog output signals produced from both types of PMT for a direct coupled scintillator. Figure 4 shows the resultant spectrum from americium 241 as produced on a multi-channel analyzer. The resolution of the $26.36-\mathrm{keV}$ gamma ray is indicated by the peak located on the upper energy side of the $17-\mathrm{keV}$ photon peak.

Tube Characteristics

The small diameter detector used in the early wound counting systems at Rocky Flats was a 10dynode photomultiplier cesium-antimony (Cs-Sb) photocathode-type device. The tube normally was supplied baseless to minimize the outside diameter of the phototube housing.

The phototube provided a cesium antimony. photocathode with a quantum efficiency varying between 10 and 16 percent. The tube was not specified for any mechanical vibration or shock capability. This type is characterized by No. 7767 , the parent-type 1.90-centimetre $(\mathrm{cm})$ diameter tube. Generally these tubes were selected for lowest background performance by assembly as a scintillation detector with a $1.90-\mathrm{cm}$ sodium iodide thallium 
FIGURE 1. Photomultiplier Tube Characteristics.

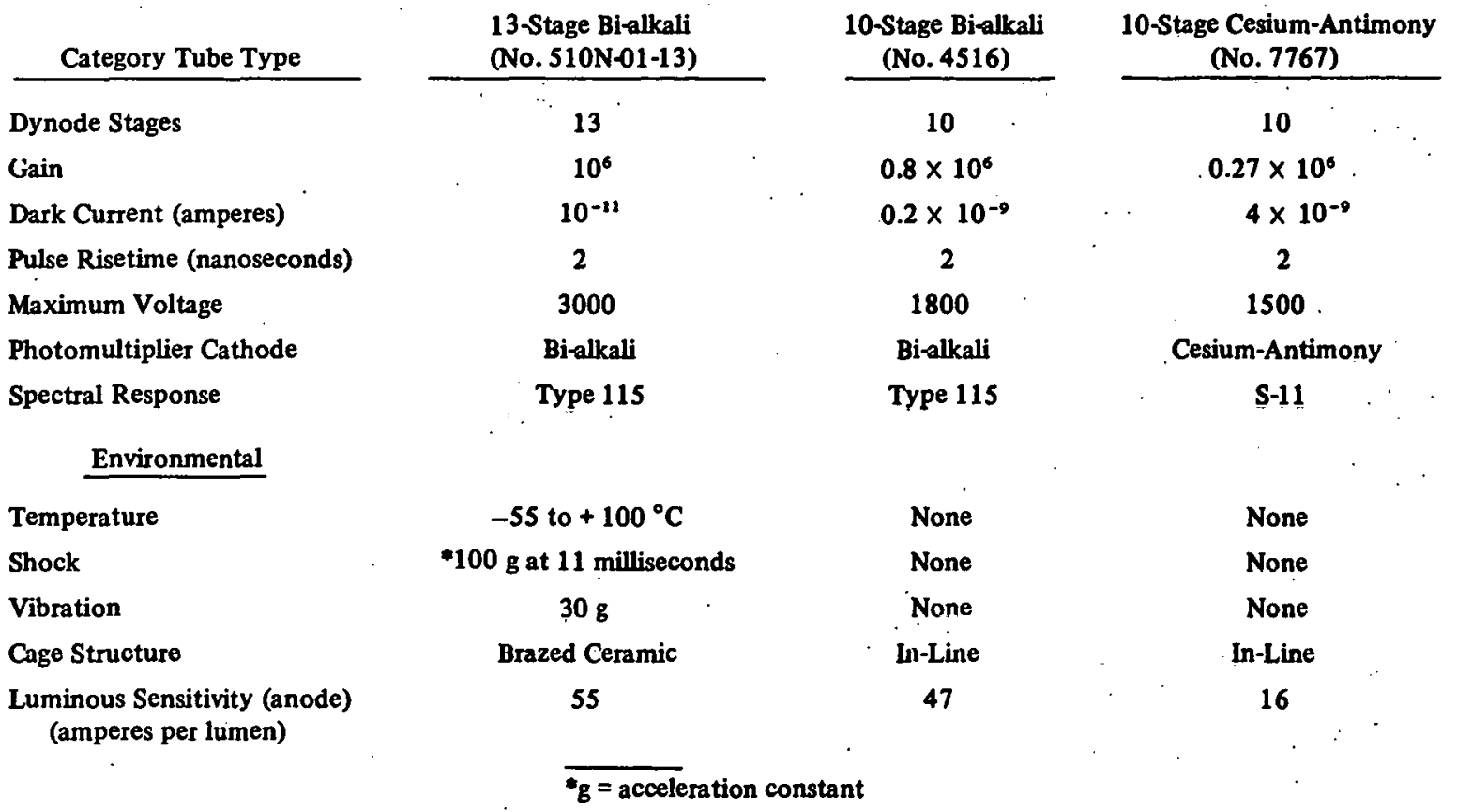

FIGUREE 2. Photocathode 10.Stage CesiumAntimony Tube (high voltage of $1000+$ ).

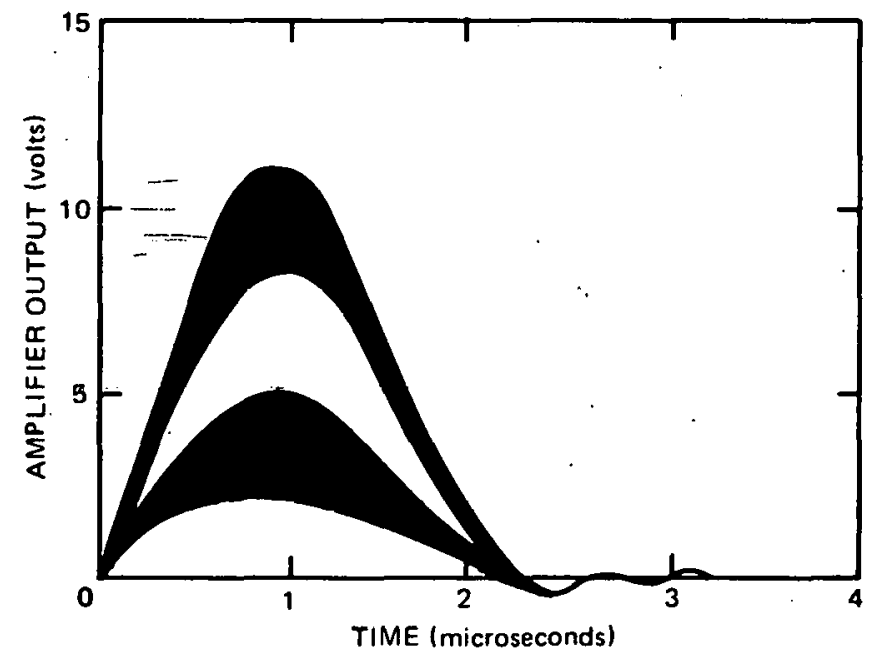

FIGURE 3. Photomultiplier 13-Stage Brazed Ceramic Tube (high voltage 2800t).

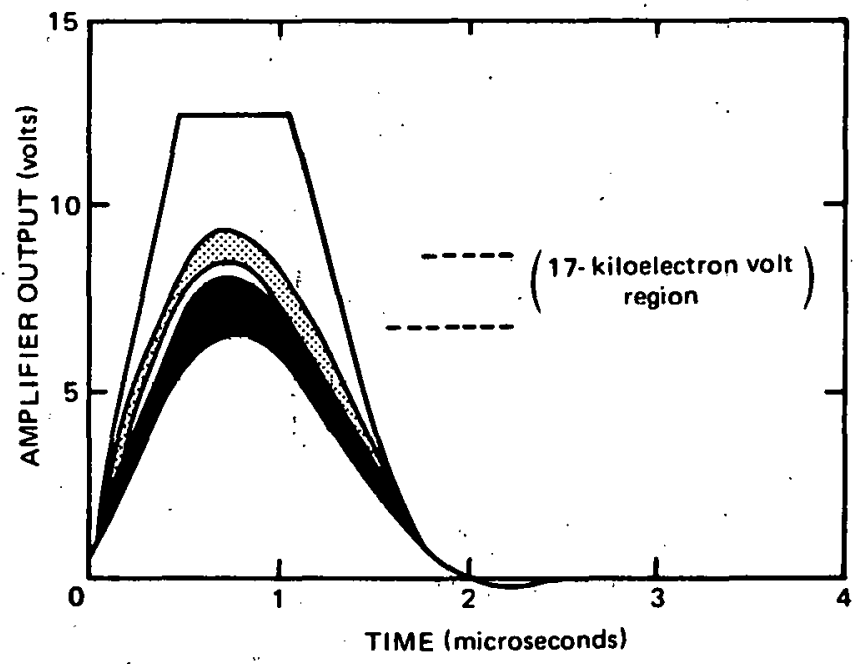



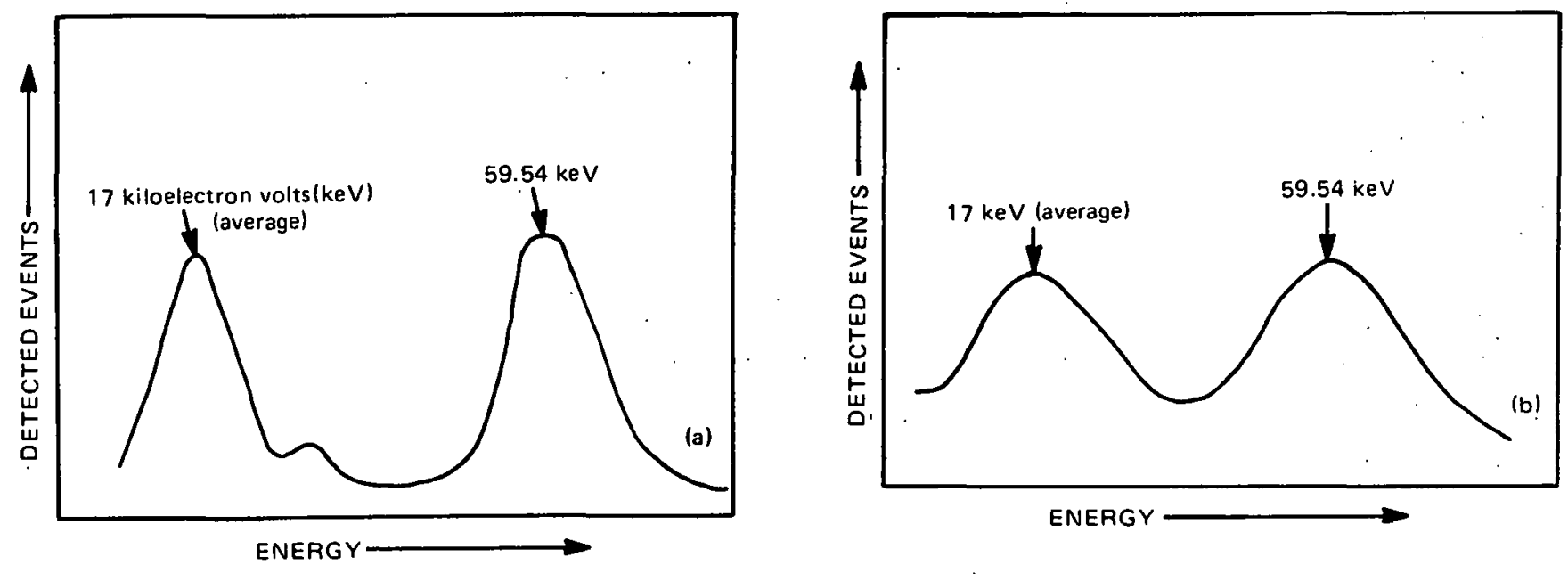

FIGURE 4. Americium-241 Source: 13Stage Photomultiplier Tube (2800 volts) (a); and 10-Stage Tube (1000 volts) (b).

[NaI(Tl)] crystal and then optimized for $17-$ kiloelectron volt ( $\mathrm{keV}$ ) photon response from a 1-microgram plutonium source. After optimization for count, a series of background measurements were made to determine the average counting rate. If the counting rate were determined to be excessive or could not be stabilized, another high voltage operating point was selected and the process repeated. The setup of a new detector turned out to be a laborious process. It required the undivided attention of a technician for several days to construct a detector and reset the operational parameters of the counting system whenever a failure of the detection portion of the system occurred.

Because of the difficulty in construction and setup of the system, varinus types of phototubes were tried to obtain a detector which was easier to construct and had more stable operating parameters. The introduction of the bi-alkali photocathode tube tended to provide a more consistent unit, but it still required individual selection of the tubes normally obtained through the local suppliers. The 10-stage bi-alkali type tube was used in the wound counters built between 1968 and 1972 . This tube is characterized by Photomultiplier 'lube (No. 4516).

\section{Performance Record}

The background count-rate performance of the various systems developed during the past 19 years is shown in Figure 5. The maximum and minimum count recorded during the useful life of each of the wound counters is shown as the upper and lower limits of the average count rate. The 13-stage PMT was introduced into wound counter operation in 1973. A reduction in background count-rate variation was produced.

\section{Source Response}

Shown in Figure 6 is the response of the scintillation detector to $17-\mathrm{keV} \mathrm{X}$-ray emissions from the decay of a 62-nanocurie plutonium-239 source. The years included in the graph correspond to those shown for the typical background performance of a particular wound-counting system.

\section{Detector Assembly}

The detector housing contains the interconnections for the photomultiplier tube high voltage bias and output connections for signal transmission to the electronic section of the unit, and a light-tight housing for mechanical protection of the tube. These housings allow gas sterilization, when the detectors are used in conjunction with surgical operations.

Figure 7 shows the typical electrical connections for the 10-stage and 13-stage photomultiplier tubes. Figure 8 shows the three detector units used with 
RFP-2570

FIGURE 5. Background Count Records.

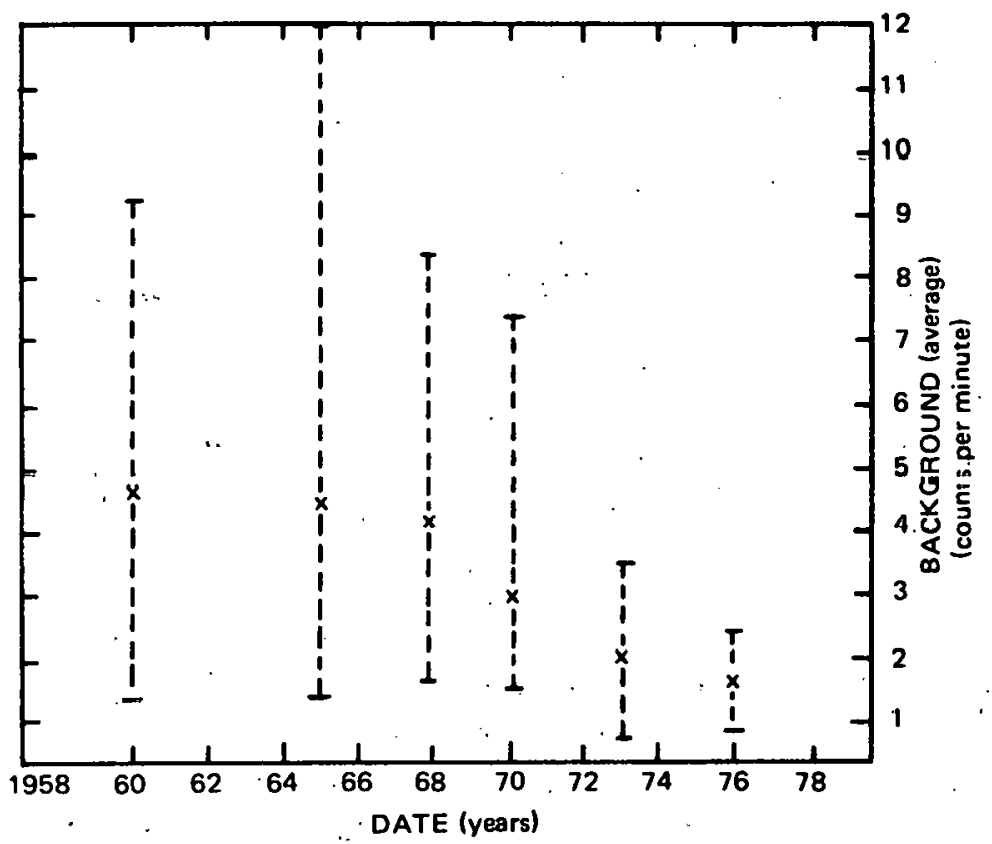

FIGURE 6. Average Response of a Small

Detector for 17-Kiloelectron Volt X-rays

Prnduced trom the Decay of Plutonium $23 \%$.

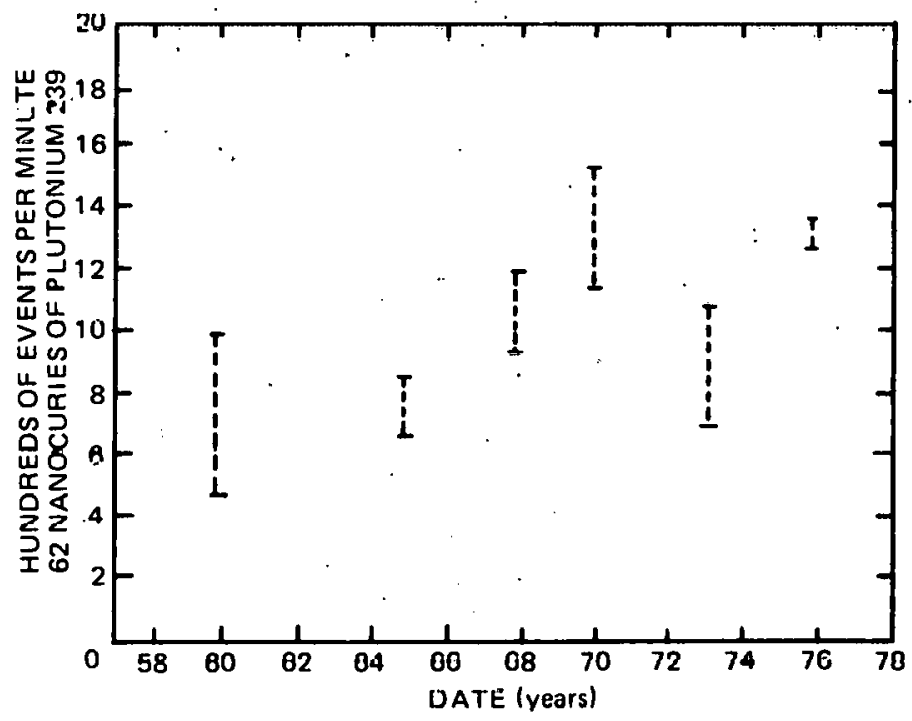




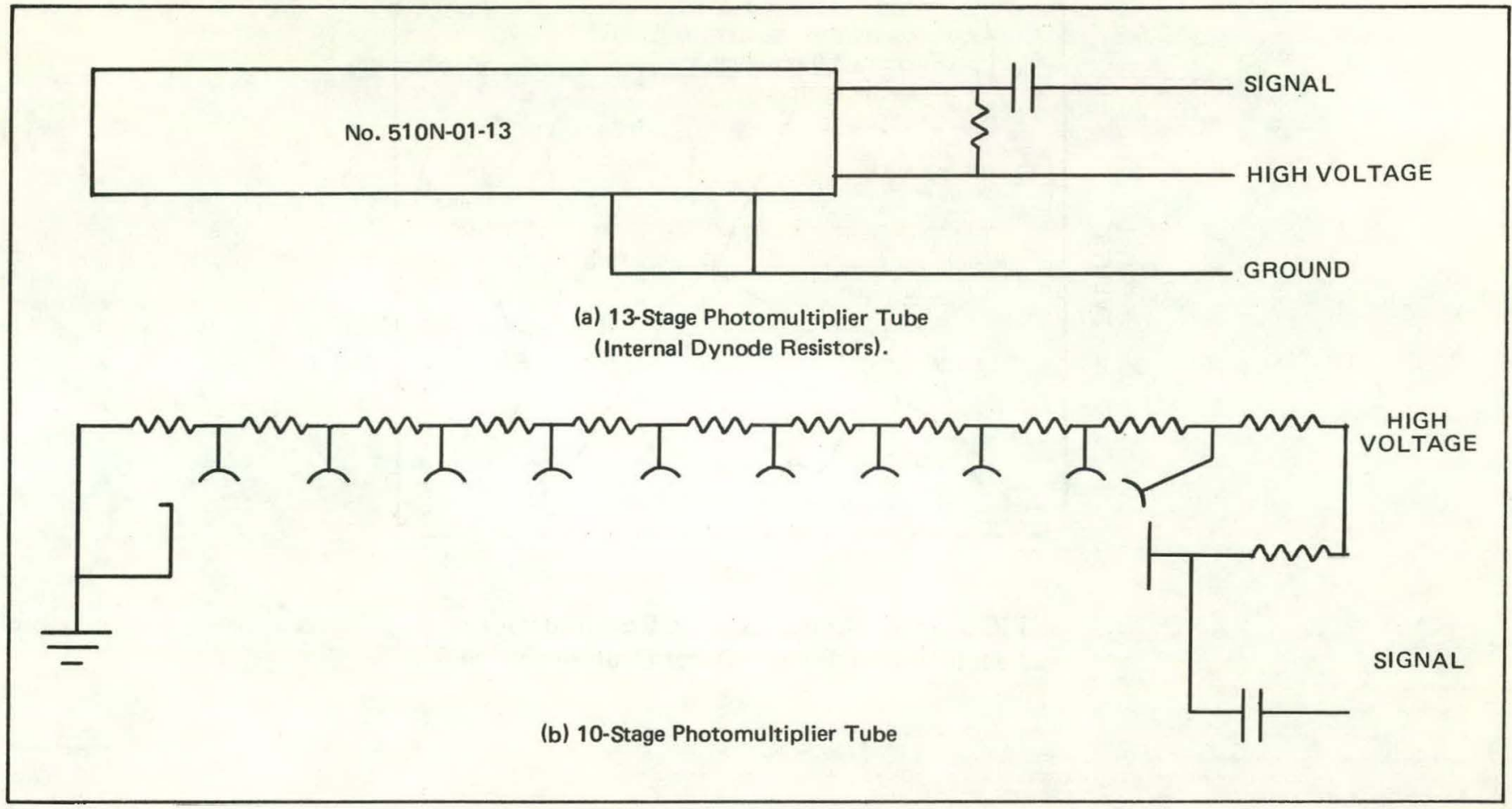

FIGURE 7. Schematic of Connections for Tube Operation.

FIGURE 8. Three Wound-Counter Detectors.

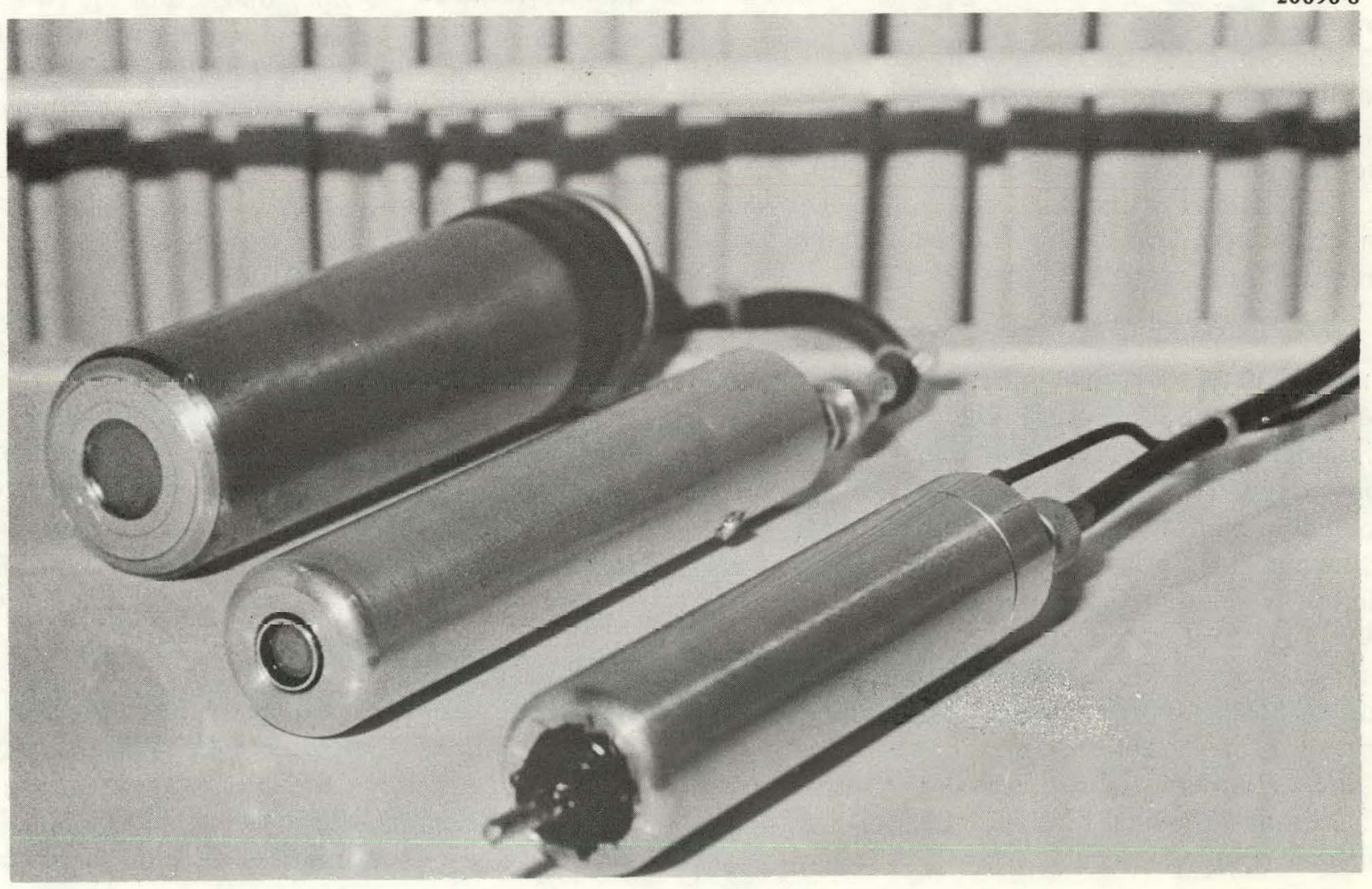




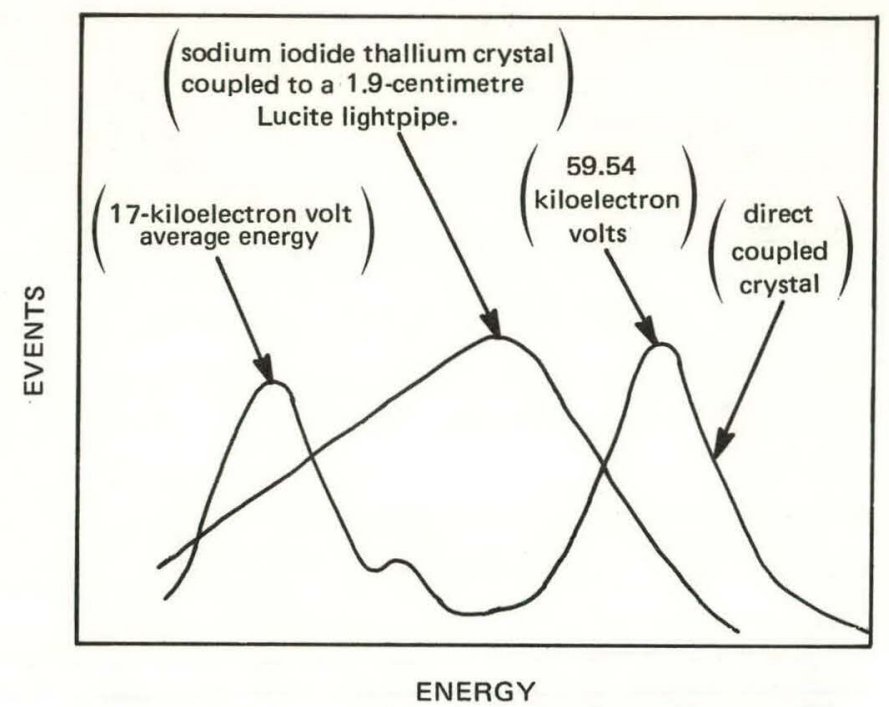

FIGURE 9. Comparison of Resolution for a Lightpipe Coupled and Direct Coupled Crystal.

the systems. The two detectors shown on the left are associated with the general purpose wound counter for specific area monitoring and wound coverage. The detector with the larger sized housing of the two uses a $1.90-\mathrm{cm} \mathrm{NaI(Tl)}$ 2-millimetre (mm) thick crystal coupled to a 3.81-cm, 10-stage photomultiplier tube (PMT) and normally is used as a substitute detector in in case of failure of the smaller detector. The second detector used a $0.95-\mathrm{cm} \mathrm{NaI(Tl),} \mathrm{2-mm} \mathrm{thick} \mathrm{crystal}$ directly coupled to the 13-stage PMT.

The third detector shown in Figure 8 uses a 13-stage PMT coupled to a $1.90-\mathrm{cm}$ Lucite lightpipe with a 2-mm diameter $\mathrm{NaI}(\mathrm{Tl})$ chip attached. The probe housing the lightpipe and scintillator is machined from aluminum with the entrance window as part of the machined housing. This produces a thick window which selectively discriminates against the low energy X-rays from either plutonium and americium and restricts usage of this detector to wounds having appreciable parts per million americium present in the contaminating material. Figure 9 compares the response of the PMT to the scintillator crystal for a direct coupled versus lightpipe coupled scintillator.
Block Diagram of Systems

Figure 10 shows the block diagram of the two systems. The counter are identical except for the method of data presentation and the lower energy transmission capability of the detector entrance window.

\section{CALIBRATION PROCEDURE}

\section{General Purpose Wound Counter:}

The initial adjustment of the high voltage for the 13-stage photomultiplier tube should be approximately 2700 volts. The output pulse amplitude from the NIM amplifier should be between 2 and 4 volts for the $17-\mathrm{keV}$ average energy X-rays from an americium-241 ( $\left.{ }^{241} \mathrm{Am}\right)$ or plutonium-239 $\left({ }^{239} \mathrm{Pu}\right)$ source for the scintillator mounted directly to the photocathode of the tube. The pulses produced from the 59.54-keV gamma ray of ${ }^{241} \mathrm{Am}$ will produce saturated conditions in the linear amplifier. The amplifier should be initially adjusted to produce amplifier output pulse decay, 
FIGURE 10. System Block Diagram.

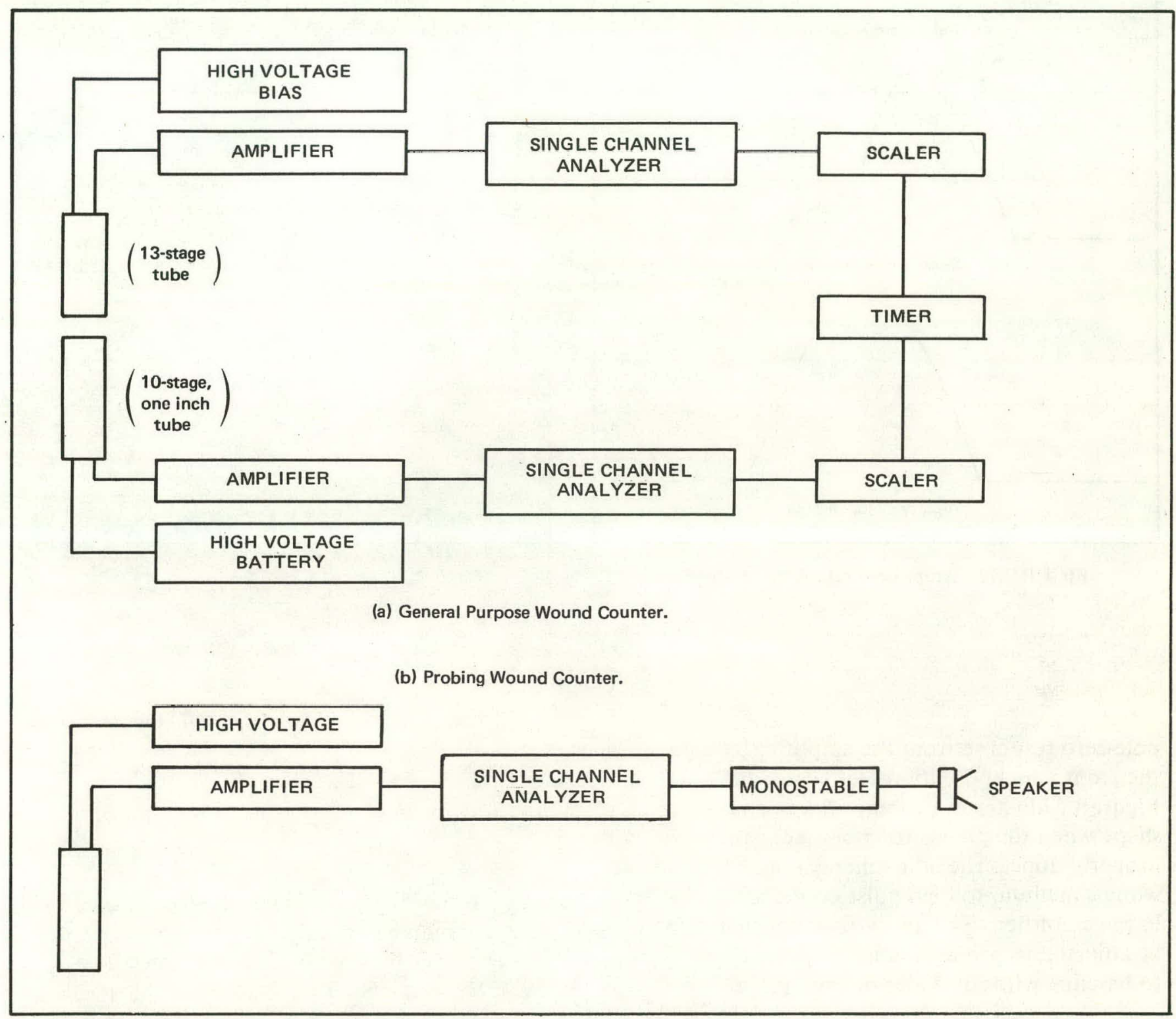




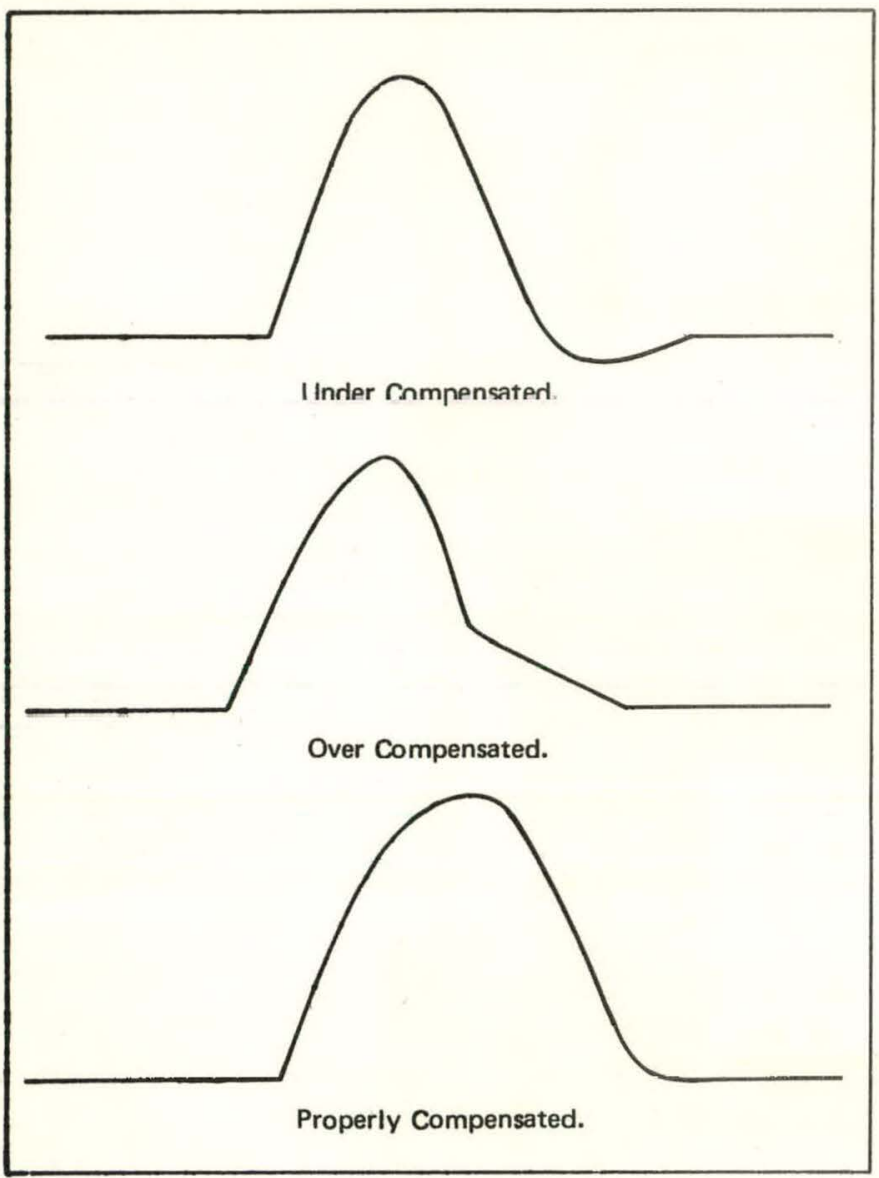

FIGURE 11. Amplifier Output Pulse Shapes.

pole-zero response from the amplifier by adjusting the front panel potentiometer labelled (PZ).

Figure 11 illustrates the amplifier output pulse shape when the pole-zero circuit adjustment is properly done. The adjustment should be done while a medium-to-high pulse count rate is present in the amplifier. The decay-time constant should be adjusted to produce unipolar pulse decay back to baseline without under or over shoot.

The lower level discriminator (LLD) and upper level discriminator (ULD), of the single channel analyzer (SCA) provide the adjustment of voltage range for selecting the amplitude of interest. The discriminator settings of the SCA should bracket the range of amplitudes present from the amplifier that represent the $17-\mathrm{keV}$ average energy

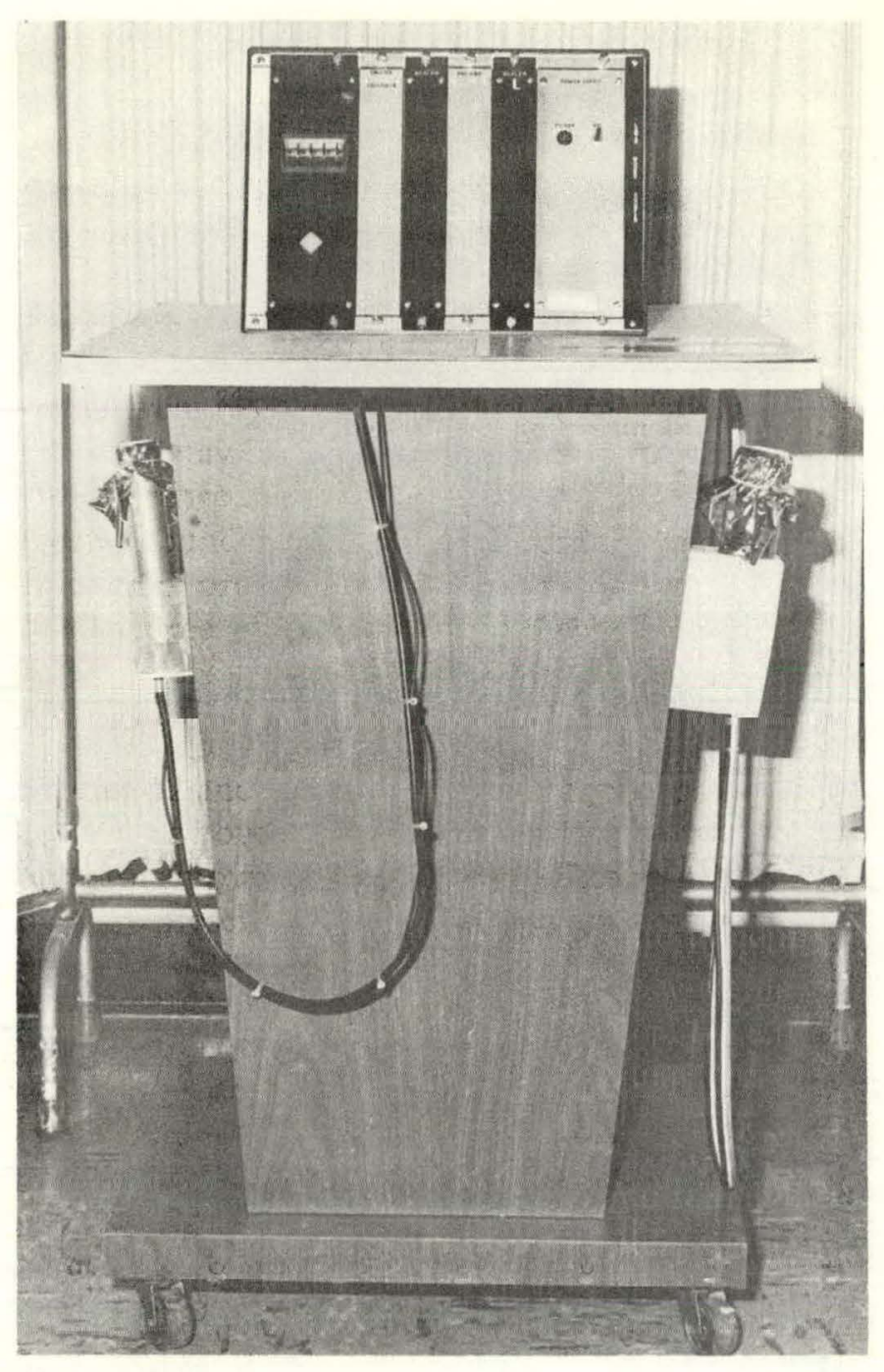

20696-2

FIGURE 12. Front View of General Purpose Counter.

either from ${ }^{241} \mathrm{Am}$ or ${ }^{239} \mathrm{Pu}$. The single-channel analyzer may be initially adjusted to the proper voltage range by using a ${ }^{241} \mathrm{Am}$ source. The greater abundance of photons from the decay of americium provides a higher count rate with the small source available in the medical department and shortens the setup time of the system.

Figures 12 and 13 show the general purpose wound counter as housed in its cabinet with the two detectors mounted on each side. The resultant data are presented on the two scalers mounted in 


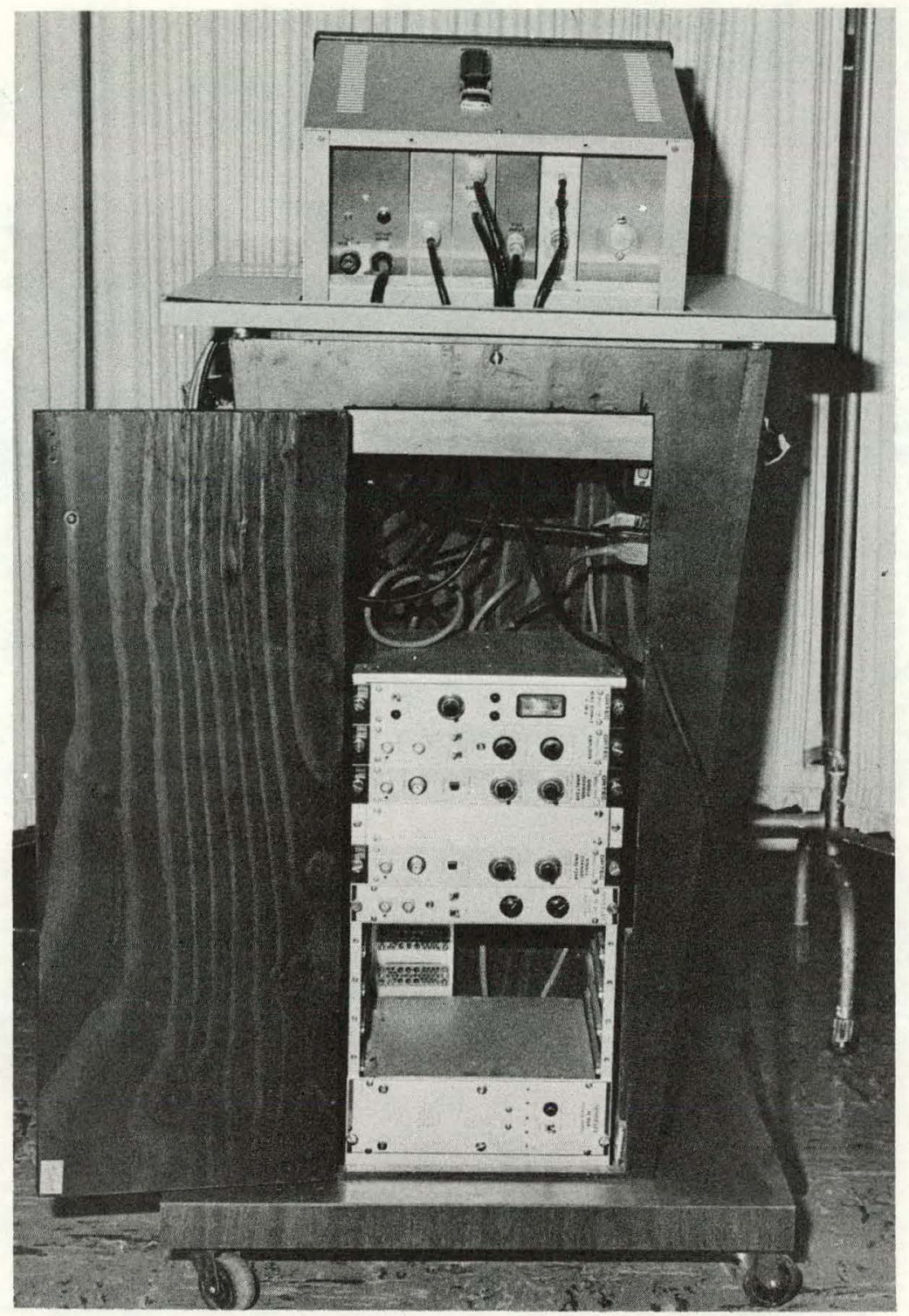

20696-4

FIGURE 13. Back View of General Purpose Counter.

the top NIM-bin cabinet. The particular detector selected is determined by the type of wound encountered. The time needed for counting is selected by the thumb-wheel switches on the timer unit located on the left side of the display unit of the wound counter. The operation of the unit requires only the placement of the detector over the wound area, manually actuating the reset button on the lower part of the timer, and then the counting begins. The events detected are displayed on the light emitting diode (LED) scaler unit associated with the detector.

\section{Isolation Count-Rate Wound Counter:}

The front end alignment of the special wound counter for determining the relative position of material in the wound is basically set up the same way as the general purpose wound counter. The 
RFP-2570

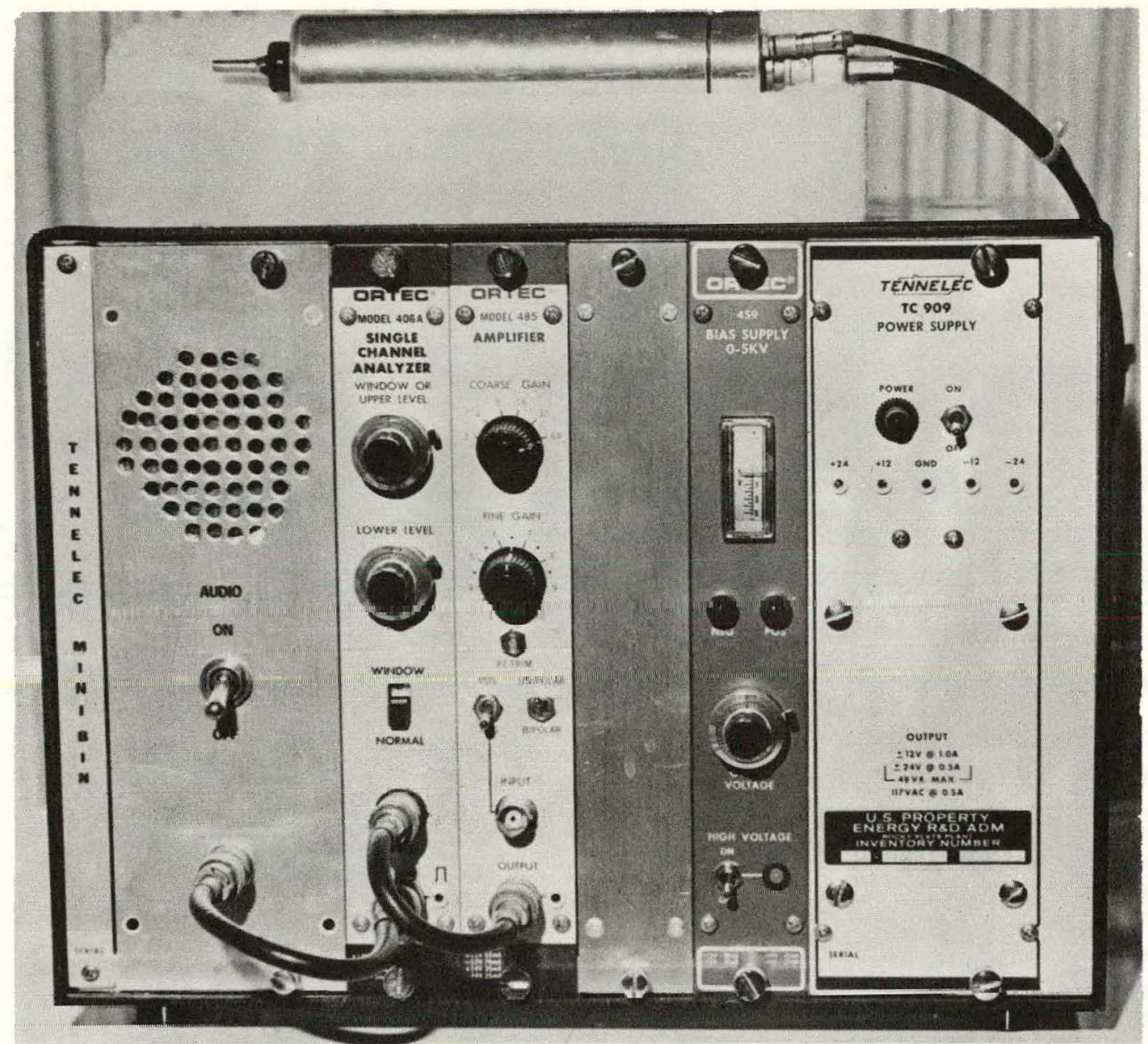

FIGURE 14. Isolation Wound Counter.

20696-7

FIGURE 15. Monostable and Speaker Driver.

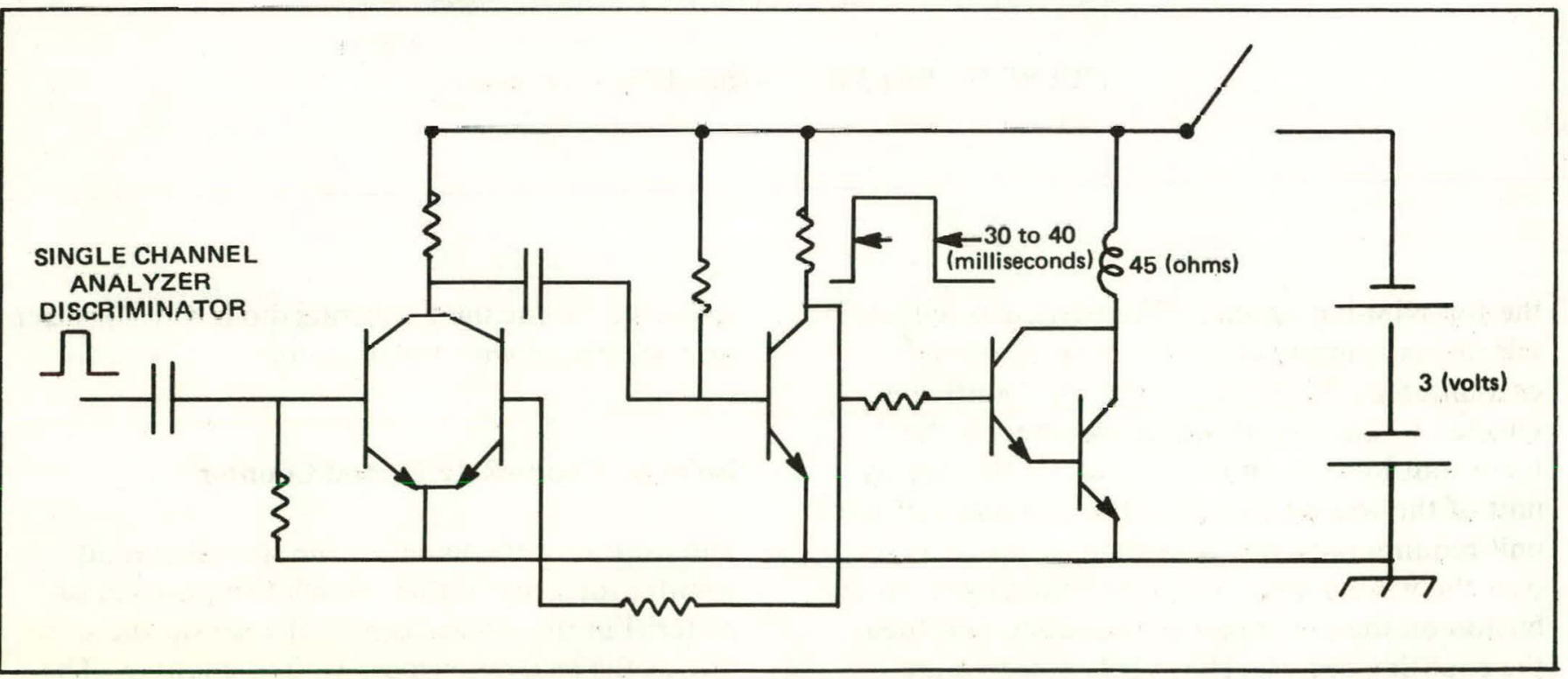


single-channel analyzer is set to include the $17-\mathrm{keV}$ region and the $60-\mathrm{keV}$ region which would be present if an appreciable amount of americium is present in the plutonium. The range of voltages represent the degraded energies present from the loss of light to the photocathode due to the optical aperture of the lightpipe and internal reflection as shown in Figure 9. The single channel analyzer is set to include a voltage range of 0.75 to 2 volts. This represents the energy range of about 10 to $60 \mathrm{keV}$, as represented by the voltage pulses produced by the scintillation detector. The output pulses produced by the single channel analyzer are about 0.5 microseconds wide. These are used to trigger a monostable multivibrator to produce pulses that are 30 to 40 milliseconds wide. These pulses then are used to operate a small speaker mounted inside the NIM module.

The upper level discriminator provides a restricted voltage range of operation to minimize background counting rate during localization of the material inside the wound. The surgeon uses the detector system by probing the wound and mentally recording the position where the greatest number of pops are heard.

Figure 14 shows the front-panel layout of the wound counter used for isolation of contamination within the wound. Since time is not a parameter in this system, the only presentation is that of the individual events by means of an aural pop. The detector provides a widc range of pulse amplitudes to trigger the audio output circuits. The singlechannel analyzer provides a normalized output signal for the range of voltages representing an an energy range of 10 to $60 \mathrm{keV}$.

The aural output for the surgical detection system includes a module containing the 30 to 40 millisecond monostable multivibrator and a speaker driver circuit for producing pops for each event detected by the scintillation detector system.

'I'he schematic of this portion of the wound counter is shown in Figure 15.
Since the relative position of the material interests the operating surgeon, quantification of the material is not required. The primary interest is to determine as accurately as possible where the material is located. The amount of material present in the excised tissue is determined after the tissure has been removed.

\section{CONCLUSIONS}

The use of a robust 13-stage photomultiplier tube provides a 50 percent reduction in background counting rate with approximately 40 percent improvement in the statistical deviation of the count rate. The improved resolution of the 13stage tube provides a 30 -percent increase in the number of detected events from a 62-nanocurie plutonium-239 source.

\section{REFERENCES}

1. K. L. Swinth, J. F. Park, G. L. Voelz, and J. H. Ewins. "In Vivo Detection of Plutonium in the Tracheo Brurichial Lymph Nodes with a Fiber Optic Coupled Scintillator." Proceedings of Hanford Biology Symposium on Radiation and the Lymphatic System. Conference 740930. Hanford Laboratory, Richland, Washington. 1976.

2. E. A. Putzier, J. R. Mann, and V. P. Johnson. "Use of a Gamma Ray Spectrometer for Investigation of Plutonium Contaminated Wounds." American Industrial Hygiene Association Journal 19:384. October 1958.

3. Robert W. Bistline and William H. Tyree. A comparison of Low Energy Photon Detectors for Plutonium and Americium Wound Counting. RFP-1068. Rocky Flats Division, Dow Chemical Company, Golden, Colorado. December 18, 1967. 
RFP-2570

THIS PAGE

\section{WAS INTENTIONALLY LEFT BLANK}

